\title{
Cochrane Canada to lose primary funding
}

$\mathrm{T}$ he Canadian Institutes of Health Research (CIHR) will not renew funding for Cochrane Canada after its existing commitment expires in September 2015. CIHR has been the primary funder, providing about $\$ 17$ million since 2005 to Cochrane Canada, which produces systematic reviews of research to promote evidence-based decision-making in health care.

"What Cochrane does is valuable to the dentist on Main Street, to the physiotherapist on Main Street, to the nurse in a station up North," said Dr. Jeremy Grimshaw, director of Cochrane Canada. "Cochrane is the interface between primary studies and health decision-making. It helps a wide range of stakeholders make evidence-informed decisions."

CIHR has funded Cochrane using a direct-grant approach, a process that is peer reviewed but noncompetitive. It is used to fund work of strategic importance that can be done by only one group. According to CIHR, there are now other parties doing similar work to Cochrane Canada.

"New actors in the field of moving research evidence into practice through the creation and updating of highquality systematic reviews now exist and CIHR believes that they deserve the same opportunity to apply through a fair process," stated a CIHR media representative in an email. "The Canadian Cochrane Centre is encouraged to apply for continued support through the same methods used by CIHR to award funding to other world-leading scientific research."

An invitation to compete in the open operating-grant process, however, is somewhat disingenuous, said Grimshaw. That process is intended for investigator-led, hypothesis-driven research. "They are basically asking a square peg to apply for a round hole," said Grimshaw. "My concern is that it will fail not because of the value of what we do but because it is the wrong funding mechanism for an enabling platform like Cochrane."

According to Grimshaw, Cochrane Canada, one of 14 Cochrane centres around the world, has been highly productive in the past five years, producing more than 300 new or updated systematic reviews, training nearly 3000 new reviewers and leading almost 100 knowledge translation events. Without the CIHR funding, that productivity will be dramatically reduced, said Grimshaw, and that will lead to a reduction in systematic-review expertise in Canada.

"It will have a reputational impact on Canada. It is remarkable that a country involved at the ground floor in Cochrane and evidence-based medicine is thinking about getting out of it," said Grimshaw. "At the moment, Canada is, sadly for us, the only geographical area where there are major concerns about Cochrane funding."

Other benefits of Cochrane Canada include collaboration with reviewers around the world, fulfillment of an international obligation to contribute to evidence-based medicine and the provision of a Canadian context for medical research, according to Dr. Jim Woodgett, director of research for the Lunenfeld-Tanenbaum Research Institute at Mount Sinai Hospital in Toronto. The value of the organization may be compromised, however, if it is forced to seek more funding from other sources.

"That is why the CIHR funding is so important. I don't think Cochrane Canada will disappear without CIHR funding, but it gave them stability and, more importantly, it gave them independence," said Woodgett. "There are alternative sources of funding but it will be more tainted."

The timing of this news also couldn't be much worse, said Woodgett, following so closely after the death of Dr. David Sackett, the first chair of the Cochrane Collaboration Steering Group. "It was just the wrong time to kick Cochrane Canada in the backside - at the same time as losing the father of this whole area of evidencebased medicine." - Roger Collier, CMAJ

CMAJ 2015. DOI:10.1503/cmaj.109-5091 